\title{
Tracking costs of virulence in natural populations of the wheat pathogen, Puccinia striiformis f.sp.tritici Bochra Bahri*1, Oliver Kaltz ${ }^{2,3}$, Marc Leconte ${ }^{1}$, Claude de Vallavieille-Pope ${ }^{1}$ and Jérôme Enjalbert ${ }^{1}$
}

Address: ${ }^{1}$ UMR BIOGER CPP, INRA Agro-Paris-Tech, BP01, 78850 Thiverval-Grignon, France, ${ }^{2}$ UPMC UnivParis 06, Laboratoire de Parasitologie Evolutive - UMR 7103, 7 quai St-Bernard, 75252 Paris, France and 3institut des Sciences de l'Evolution - UMR 5554, Université Montpellier 2, Place E. Bataillon (CC065), 34095 Montpellier Cedex 05, France

Email: Bochra Bahri* - bochra.bahri@grignon.inra.fr; Oliver Kaltz - oliver.kaltz@univ-montp2.fr; Marc Leconte - leconte@grignon.inra.fr; Claude de Vallavieille-Pope - pope@grignon.inra.fr; Jérôme Enjalbert - enjalber@grignon.inra.fr

* Corresponding author

Published: 30 January 2009

BMC Evolutionary Biology 2009, 9:26 doi:10.1/86/I47|-2|48-9-26

This article is available from: http://www.biomedcentral.com/I47I-2/48/9/26

(c) 2009 Bahri et al; licensee BioMed Central Ltd.

This is an Open Access article distributed under the terms of the Creative Commons Attribution License (http://creativecommons.org/licenses/by/2.0), which permits unrestricted use, distribution, and reproduction in any medium, provided the original work is properly cited.
Received: 22 August 2008

Accepted: 30 January 2009

\begin{abstract}
Background: Costs of adaptation play an important role in host-parasite coevolution. For parasites, evolving the ability to circumvent host resistance may trade off with subsequent growth or transmission. Such costs of virulence (sensu plant pathology) limit the spread of all-infectious genotypes and thus facilitate the maintenance of genetic polymorphism in both host and parasite. We investigated costs of three virulence factors in Puccinia striiformis f.sp.tritici, a fungal pathogen of wheat (Triticum aestivum).

Results: In pairwise competition experiments, we compared the fitness of near-isogenic genotypes that differed by a single virulence factor. Two virulence factors (vir4, vir6) imposed substantial fitness costs in the absence of the corresponding resistance genes. In contrast, the vir9 virulence factor conferred a strong competitive advantage to several isolates, and this for different host cultivars and growing seasons. In part, the experimentally derived fitness costs and benefits are consistent with frequency changes of these virulence factors in the French pathogen population.

Conclusion: Our results illustrate the variation in the evolutionary trajectories of virulence mutations and the potential role of compensatory mutations. Anticipation of such variable evolutionary outcomes represents a major challenge for plant breeding strategies. More generally, we believe that agro-patho-systems can provide valuable insight in (co)evolutionary processes in host-parasite systems.
\end{abstract}

\section{Background}

Central to many concepts in evolutionary biology is the idea that adaptation is not cost-free $[1,2]$. Costs arise if adaptation in one trait is opposed by a negative correlated response to another trait. Such trade-offs between fitness components can influence life-history evolution, ecologi- cal specialisation and more generally, the maintenance of genetic diversity [3].

Costs of adaptation also play an important role in hostparasite coevolution. In the host, costs of resistance refer to trade-offs between resistance and other fitness-relevant 
traits, conferring a selective disadvantage to resistant genotypes in the absence of the parasite. The corresponding costs in the parasite, referred to as 'costs of virulence' in the plant-pathogen literature, are trade-offs between the capacity to establish an infection and other parasite characters (e.g., within-host growth, production of transmission stages [4]). These costs are considered major ingredients of the coevolutionary process because they can prevent the spread to fixation of all-resistant host or all-infectious parasite genotypes and thereby preserve genetic diversity in both host and parasite populations [5$8]$.

While costs of resistance have been investigated in various host-parasite systems (plant: [9,10]; (cyano)bacteria: [11,12]; protozoa: [13]; drosophila: [14]), still little is known about costs of virulence and their role in shaping genetic structure and coevolutionary dynamics. Historically, this issue has first been addressed in plant-pathogen interactions $[15,16]$. Here, virulence refers to the ability of the pathogen to circumvent host resistance and establish an infection. This ability often arises from mutational loss of function of genes that would otherwise elicit a defense reaction of the host [17]. However, this advantage of malfunctioning can turn into a disadvantage if these genes are essential for subsequent development of infection. With the advent of molecular techniques, investigation of the precise genetic and physiological basis of costs of virulence has become possible. Induced mutagenesis of genes implicated in plant-pathogen recognition revealed that at least some of these genes are involved in within-host replication, pathogenicity or spore production [18-20]. Thus, loss of function of these genes will allow infection, but also impose a straightforward cost for subsequent development.

Given their intrinsic fitness costs, selection should eliminate unnecessary virulence genes from the pathogen population and favour pathotypes with particular virulence genes that match the resistance structure of the host population [21]. Thus, in classical models of plant-pathogen coevolution, changes in the frequencies of resistance and virulence genes are essentially determined by the fitness trade-offs associated with these genes $[6,15]$. While more recent theoretical developments balance the importance of cost with other biological features $[22,23]$, empirical and experimental evidence of these basic theoretical concepts is still scant. Natural populations of various pathogens often harbour genotypes carrying different numbers of virulence alleles. For pathogens of crop plants, withdrawal of a particular cultivar sometimes leads to the subsequent decrease in frequency of the genotypes carrying the corresponding virulence allele $[24,25]$, consistent with the idea of selection against unnecessary and costly virulence alleles. In some cases, molecular analysis sug- gests that costs of virulence contribute to the maintenance of genetic polymorphism in the pathogen [26]; in yet other cases, elimination of the function of virulence genes seems to be cost-free, suggesting that fitness costs are not universal and depend on the gene or the pathogen considered.

Only few experimental studies compared the relative fitness of naturally occurring pathogen genotypes that carry different numbers of virulence alleles. Thrall and Burdon [27] detected a negative correlation between virulence and spore production for the plant pathogen Melampsora lini. This trade-off may explain why relatively avirulent strains dominated susceptible host populations. Furthermore, for different plant-pathogen systems, competition experiments compared pathogen genotypes with different numbers of virulence alleles. Some of these studies demonstrated a selective advantage of simpler over complex genotypes, at least in the greenhouse $[[19,27,28]$, but see [29]]. Typically, however, these experiments did not control for the genetic background of the competing strains and it is possible that fitness differences were caused by other genes [30].

Here, we investigated costs of virulence in the yellow rust fungus, Puccinia striiformis f.sp.tritici (PST), one of the most damaging wheat pathogens worldwide [31]. This clonally reproducing pathogen rapidly evolves through stepwise mutational acquisition of new virulences $[32,33]$, and the resulting arms race between plant breeders and the pathogen is characterised by frequent and rapid resistance breakdowns [34]. In North-Western Europe, the fitness advantage of being able to grow on a resistant cultivar is so strong that a new virulent mutant pathotype can replace an existing dominant pathotype within 2-3 years $[33,35]$. Costs of virulence potentially slow down resistance breakdowns or at least limit the severity of epidemics. Therefore knowledge of these costs can help plant breeders to better understand evolutionary change in the pathogen and to develop more efficient strategies of resistance management.

We performed competition experiments using pathogen genotypes that differed by a single virulence gene not needed for infection. This is analogous to measuring costs of resistance in the absence of the parasite $[4,10]$. If the virulence gene is costly, its carriers should be at a competitive disadvantage. We tested this hypothesis for different naturally occurring virulence genes. The specific novelty of this study is that we explicitly accounted for genetic background by competing genotypes with identical (or nearly so) profiles of molecular markers (AFLP). Because this pathogen is clonal, identical profiles indicate very close phylogenetic relationships. Further, competition assays were carried out both in the climatic chamber and 
in the field, on different wheat cultivars and in different years. We confront our results with changes in the frequencies of these virulence factors in natural populations over the past 20 years [34], and with changes in aggressiveness in a collection of isolates from this period.

\section{Results}

\section{Competition experiments}

The 16 isolates used in these experiments were collected from naturally infected fields in France between 1989 and 1997. Competition experiments were carried out between pairs of fungal isolates with identical AFLP marker profiles (see methods). These isolates also had identical virulence gene profiles, except that one of the two isolates carried one additional virulence gene (Table 1). The isolate with the additional virulence gene will be referred to as 'virulent' (vir), the one without it as 'avirulent' (Avir). By definition, virulent isolates are fully infective (fitness $=1$ ) on resistant plants, whereas avirulent isolates cannot infect these plants (fitness $=0$ ). Remember that 'virulent' here is used in the plant pathology sense, i.e., it refers to the capacity to infect a host; to describe the damage done to the host, we use the term 'aggressiveness' [36]. In the present experiments, host varieties were chosen such that both types of isolates were infectious, that is, the additional virulence gene was redundant with respect to infectivity of the isolate and thus potentially costly. We tested the effects of three virulence genes vir9, vir6 and vir4 in field experiments, with an additional focus on vir9 in controlled conditions.

\section{vir9 pathotype}

In a climate chamber assay, we competed two independent pairs $(A, B$, see Table 1$)$ of a virulent and an avirulent isolate, initially in a 50:50 mix. For pair $A$, the relative frequency of the isolate (i5) with the additional virulence allele decreased by $50 \%$ over the course of five infection cycles, and this on both host cultivars (Figure 1). For pair $B$, deviations from the 50:50 ratio were less pronounced and differed between host cultivars (pair $\times$ host cultivar $\times$ time interaction: $\mathrm{F}_{4,16}=3.67, \mathrm{p}=0.0263$; repeated measure ANOVA).

In field competition assays, the relative frequencies of avirulent and virulent isolates at the end of the growing season varied strongly among four independent pairs $(A, B$, $C$, $D$; Figure 2a, Table 2). Starting from an initial 50:50 ratio, the relative frequency of the virulent isolate (i5) in pair $A$ decreased significantly by about $50 \%$, just like in the greenhouse assay. In contrast, virulent isolates $(i 6, i 7$, $i 8$ ) doubled in frequency in the three other pairs $(B, C, D)$. With one exception (pair B, 2005, on the Récital cultivar), these patterns were consistent over growing seasons (2005, 2006) and host plant cultivars (Récital, Thésée) (Table 3). Thus, in one case (i5), the isolate with the additional virulence was less competitive than its isogenic counterpart; in the three other cases, it was more competitive $(i 6, i 7, i 8)$. The selective advantage or disadvantage of these virulent isolates was in the order of $15-20 \%$.

Table I: Identity of pathogen isolates in the pairwise competition experiments

\begin{tabular}{|c|c|c|c|c|c|c|c|c|c|c|c|c|c|c|c|c|c|}
\hline Virulence & Pathotype & & & rule & ce & acto & $r \mathrm{pr}$ & file $^{2}$ & & Isolate & Reference $^{3}$ & & & & & & \\
\hline \multirow[t]{4}{*}{ Avir9 } & I09EI4I-Avir I 7 & I & 2 & 3 & 4 & 6 & - & $S D$ & - & il & J89138 & A & & & & & $\mathrm{F}$ \\
\hline & & & & & & & & & & $i 2$ & J89110 & & B & & & $\mathrm{E}$ & \\
\hline & & & & & & & & & & $i 3$ & J886IM & & & $C$ & & & \\
\hline & & & & & & & & & & i4 & J89122 & & & & $\mathrm{D}$ & & \\
\hline \multirow[t]{4}{*}{ vir9 } & 237EI4I-Avir I 7 & I & 2 & 3 & 4 & 6 & 9 & $S D$ & - & i5 & J89121 & $A$ & & & & $\mathrm{E}$ & \\
\hline & & & & & & & & & & i6 & J89137 & & B & & & & $\mathrm{F}$ \\
\hline & & & & & & & & & & i7 & J952IMI & & & C & & & \\
\hline & & & & & & & & & & i8 & j9522M2 & & & & $D$ & & \\
\hline \multirow[t]{2}{*}{ Avir4 } & I73E|40-vir/ 7 & I & 2 & 3 & - & 6 & 9 & $S D$ & 17 & i9 & J99198 & G & & & & & \\
\hline & & & & & & & & & & ilo & J0085F & & $\mathrm{H}$ & & & & \\
\hline \multirow[t]{2}{*}{ vir4 } & 237EI4I-vir/ 7 & I & 2 & 3 & 4 & 6 & 9 & $S D$ & 17 & ill & J0I I44B-MI & G & & & & & \\
\hline & & & & & & & & & & il2 & J02022 & & $\mathrm{H}$ & & & & \\
\hline \multirow[t]{2}{*}{ Avir6 } & I69E|36-vir/7 & I & 2 & 3 & - & - & 9 & $S D$ & 17 & i/3 & J979IM & 1 & & & & & \\
\hline & & & & & & & & & & il 4 & j9782 & & J & & & & \\
\hline \multirow[t]{2}{*}{ vir6 } & |73E|40-vir| 7 & I & 2 & 3 & - & 6 & 9 & $S D$ & 17 & il5 & j02022 & 1 & & & & & \\
\hline & & & & & & & & & & il6 & J02055C & & J & & & & \\
\hline
\end{tabular}

Three virulence factors (vir9, vir4, vir6) were tested, with 16 natural isolates (il-il6) of $P$. striiformis f.sp. tritici. For each of the 10 pairs (A-J), the two competing isolates had (nearly) identical AFLP profiles and identical virulence factor profiles, except for the virulence factor to be tested (marked in bold). The isolate carrying the additional virulence gene is referred to as virulent (vir), the one without it as avirulent (Avir). ' Nomenclature determined by reactions on a set of European and world differential cultivars; ${ }^{2}$ SD refers to virulence on the cultivar Strubes Dickkopf; ${ }^{3}$ Lab references of each isolate. The two numbers after the "J" denote year of sampling of the isolate. 


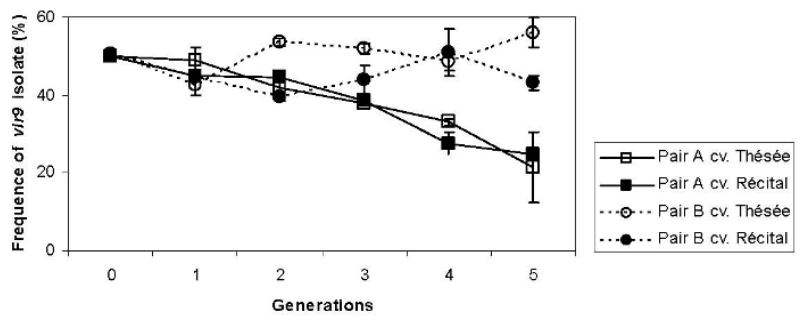

Figure I

Competitive success of vir9 isolates in the climate chamber experiment. Mean ( \pm S.E.) frequencies of vir9 isolates relative to avir9 isolates over the course of 5 pathogen generations in pairwise competition experiments. Two $A$ vir/vir pairs $(A, B)$ were competed on two host cultivars (Thésée, Récital). Each point represents the mean and S.E. calculated over 2 independent replicates.

With two additional competition pairs (E, F) we were able to compare all possible A vir/vir combinations between the i1, i2, i5 and i6 isolates. Analysis of this set of combinations (pairs A, B, E, F) revealed a significant effect of virulence identity (i5 vs. i6; F1, $8=142.61, \mathrm{p}=<0.0001$ ), but no significant interaction between avirulence and virulence identity $(\mathrm{F} 1,8=0.05, \mathrm{p}=0.832)$. That is, the i5 isolate was less competitive and the i6 more competitive, regardless of the identity of the avirulent counterpart in the mix.

\section{vir4 and vir6 pathotypes}

For the vir4 and vir6 pathotypes, four pairs of avirulent and virulent isolates were tested (Pairs G-J, Table 2) under field conditions. For all virulent isolates, we observed a significant decrease in the frequency (vir4: $\mathrm{t}_{7}=12.76, \mathrm{p}<0.0001$; vir6: $\mathrm{t}_{5}=5.19, \mathrm{p}=0.0035$ ) (Figure $2 \mathrm{~b}$, Table 2). Typically, their relative frequencies dropped from initially $50 \%$ to around $20-30 \%$ within a growing season, although this effect varied to some extent between years (vir4: year $\times$ cultivar interaction: $\left.\mathrm{F}_{1,6}=17.4, \mathrm{p}=0.0059\right)$ and host cultivars (vir6: year $\times$ pair interaction: $\mathrm{F}_{1,8}=7.44, \mathrm{p}=0.0260$ ). Thus, in all four pairs tested, the isolate with the additional virulence was substantially less competitive, with a selective disadvantage of $17-24 \%$.

\section{Sporulation test and genetic analysis of the vir9 pathotype}

We further investigated temporal changes in the genetic composition of the French population for the vir9 pathotype. To this end, we characterised AFLP profiles and measured aggressiveness of 33 vir 9 isolates collected between 1989 and 1997. Despite thorough screening of 39 primer combinations, no variation in the neutral markers was detected, indicating that these isolates all belonged to the same clonal line of descent. In contrast, isolates differed significantly in their aggressiveness, as measured by the infection type (IT) index $\left(\mathrm{F}_{32,71}=8.39, \mathrm{p}\right.$ $=<0.0001$; Figure 3). This visual classification index was highly correlated with quantitative measurements of sporulation rate $(\mathrm{r}=0.75, \mathrm{n}=185, \mathrm{p}=<0.0001)$, showing an up to 5 -fold difference in sporulation rate between isolates. After the resistance breakdown of the $\mathrm{Yr} 9$ cultivar in 1989, a first epidemic occurred between 1989 and 1991, a second between 1993 and 1997. In the collection, the variance in IT significantly decreased between the first and the second epidemic period $\left(\mathrm{F}_{1,31}=5.1880, \mathrm{p}=0.0298\right.$ in

Table 2: Success of virulent isolates in pairwise competition experiments in the field

\begin{tabular}{|c|c|c|c|c|c|c|c|c|}
\hline \multirow[t]{2}{*}{ Avir/vir competition } & \multirow[t]{2}{*}{ Pair } & \multirow[t]{2}{*}{ Avir } & \multirow[t]{2}{*}{ vir } & \multicolumn{2}{|c|}{ Year I } & \multicolumn{2}{|c|}{ Year 2} & \multirow[t]{2}{*}{ Selective value of Avir } \\
\hline & & & & Cultivar I* & Cultivar 2** & Cultivar I* & Cultivar $2^{* *}$ & \\
\hline \multirow[t]{6}{*}{ Avir9/vir9 } & $A$ & il & i5 & $38 \pm 2.7$ & $26 \pm 0.2$ & $24 \pm 1$ & $32 \pm 10.2$ & 0.15 \\
\hline & $E$ & $i 2$ & i5 & - & - & $26 \pm 9.8$ & $32 \pm 0.2$ & 0.16 \\
\hline & $B$ & i2 & i6 & $80 \pm 3.5$ & $46 \pm 6.4$ & $74 \pm 0.2$ & $76 \pm 0.3$ & -0.17 \\
\hline & $F$ & il & i6 & - & - & $71 \pm 0.9$ & $83 \pm 0.3$ & -0.27 \\
\hline & $C$ & i3 & i7 & $85 \pm 4.4$ & $70 \pm 11.6$ & $74 \pm 5.3$ & $83 \pm 3.3$ & -0.29 \\
\hline & $D$ & $i 4$ & i8 & $83 \pm 8.6$ & $72 \pm 5$ & $70 \pm 3.2$ & $85 \pm 5.1$ & -0.28 \\
\hline \multirow[t]{2}{*}{ Avir4/vir4 } & $G$ & i9 & ill & - & - & $22 \pm 0.1$ & $18 \pm 0.9$ & 0.24 \\
\hline & $H$ & ilo & il2 & $23 \pm 0.8$ & $44 \pm 6.3$ & $28 \pm 5.1$ & $20 \pm 0.3$ & 0.17 \\
\hline \multirow[t]{2}{*}{ Avir6/vir6 } & 1 & il3 & il5 & $17 \pm 1.4$ & $14 \pm 1.9$ & $25 \pm 6.1$ & $25 \pm 0.9$ & 0.24 \\
\hline & $J$ & il 4 & il6 & $29 \pm 14.5$ & $28 \pm 9.9$ & $20 \pm 2.2$ & $12 \pm 1.9$ & 0.22 \\
\hline
\end{tabular}

Mean ( \pm S.E.) frequencies (\%) of virulent (vir) isolates relative to avirulent (Avir) isolates, measured at the end of the growing season. Different pairs $(A-J)$ were set up for each of 3 virulence genes $(9,4,6)$. Each pair was started from an initial 50:50 ratio and competed on two host cultivars and in two field seasons (year). Selective values of Avir isolates were estimated according to Leonard [28] and represent averages over cultivars and years. *Cultivar I correspond to cv. Thésée for Avir9/vir9 and cv. Audace for Avir4/vir4 and Avir6/vir6, respectively. ** Cultivar 2 correspond to cv. Récital for Avir9/vir9 and cv. Baltimore for Avir4/vir4 and Avir6/vir6, respectively. 
Table 3: Statistical analysis of competitive success of vir9 isolates in the field competition experiments

\begin{tabular}{lccccc}
\hline Source & denm. & DF & MD & F & Pr $>$ F \\
\hline Year & $1+3-5$ & $1, I$ & 1.13 & 0.09 & 0.8072 \\
Cultivar & $2+3-5$ & $1, I$ & 10.71 & 0.88 & 0.5203 \\
Pair & $1+2-5$ & 3,4 & 47.80 & 15.57 & 0.0114 \\
Year*Pair (I) & 4 & 3,3 & 1.84 & 3.23 & 0.1807 \\
Cultivar*Pair (2) & 4 & 3,3 & 1.45 & 2.54 & 0.2321 \\
Year*Cultivar (3) & 4 & 1,3 & 11.36 & 19.93 & 0.0209 \\
Year*Cultivar*Pair (4) & 5 & 3,16 & 0.57 & 0.57 & 0.6438 \\
Residual (5) & & 16 & 1.00 & - & - \\
\hline
\end{tabular}

Based on a logistic regression, Analysis of Deviance tested for effects of pair (Avir/vir), host cultivar and year on final frequencies of vir9 isolates. Analogous to Analysis of Variance, mean deviances (MD = 2.log-likelihood ratio/DF) were used to calculate quasi- $F$ values. The denominator (denm.) column indicates the error terms used for the F-tests; where necessary, linear combinations of different model factors were made [69]. The DF column indicates the numerator and denominator degrees of freedom. All factors were considered as random effects. Model fitting was analogous to SAS-type II model fitting [68]

O'Brien), with a concomitant $9 \%$ increase in the mean IT index. We found a considerably higher frequency of heavily sporulating isolates (IT index $>7$ ) during the second epidemic $\left(\chi^{2}(1)=4.04, \mathrm{p}=0.044\right.$; Figure 3$)$. These changes suggest a response to natural selection in aggressiveness during the two epidemics. Finally, note the link between performance in the competition assays and sporulation rate: the less competitive i5 isolate had a much lower sporulation rate $(0.17 \pm 0.08 \mathrm{mg}$ spores/chlorose) than the three more competitive isolates $(i 6, i 7, i 8$ : 0.37-0.53; see also Figure 3).

\section{Discussion \\ Evidence for costs of virulence}

For five of the 8 virulent isolates tested, our experiments demonstrated a substantial cost of carrying an additional virulence gene, and this for different genes and different genetic backgrounds of the same gene. Despite some variation between years and cultivars, these costs appear to be quite robust and repeatable. In particular, the additional tests (pairs $E, F$ ) showed that the low performance of the virulent isolates was independent of the identity of the avirulent competitor.

Genetic variation in fitness detected in the laboratory does not always reflect the degree of variation expressed under field conditions. Under natural conditions, stress can increase the genetic variance in fitness [37], while confounding environmental effects might limit its detection [38]. Here, the field assays revealed even stronger fitness differences between the competing isolates (Figure 2). The selection coefficients $(13 \%-22 \%)$ are similar to those from laboratory studies on other organisms [39-41] and indicate potentially strong selection against these viru- lence genes, if redundant. The most likely cause of this competitive disadvantage is a reduction in the ability to develop on the host and produce spores. This type of cost has been detected in other pathogens [39-43] and at least for the vir9 virulence gene, we have direct evidence that costs are due to low sporulation.

\section{Compatibility with epidemiological history of natural PST populations}

In agricultural host-parasite arms races, farmers typically plant one or a few host cultivars over large geographic areas. This imposes strong, uniform selection on the pathogen to evolve the ability to attack these host genotypes. In the case of PST, the necessary virulence genes to overcome resistance can rapidly arise through mutation in large clonal populations. Once a resistance breakdown has occurred, cultivars are withdrawn and replaced by new resistant cultivars, developed by plant breeders. Indeed, one of the to date most convincing examples of such a semi-natural coevolutionary arms race has been demonstrated for the PST-wheat system [34], and it involves the virulence genes (vir4, vir6, vir9) studied in our experiments. With the replacement of susceptible cultivars, the vir6 and vir9 genes have become redundant at some point during the past 15 years (vir4 has always been redundant). Thus, if these genes impose fitness costs, they should have decreased in frequency in natural pathogen populations[21].

For the vir6 virulence gene, this seems to be the case. The competition experiment revealed a strong selective disadvantage of the virulent vir6 isolates, and this is consistent with three declines in the frequency of the vir6 gene, when cultivars carrying the corresponding resistance gene ( $\mathrm{Yr} 6)$ were retracted [34]. In contrast, the fitness costs of the vir4 virulence gene detected in the competition experiment does not match with its epidemiological history. The vir4 gene appeared in Europe already more than 20 years ago[34,44] and all contemporary pathotypes carry it. Interestingly, the majority of plant varieties used in France in the past 30 years did not carry the corresponding Yr4 resistance gene and thus the vir4 gene must have been mostly redundant. Given the clonal evolution of PST, it is possible that this ancestral vir4 gene has spread to fixation by hitch-hiking with new, selectively advantageous virulence genes. Originally, the vir4 gene may have immigrated from the UK, where the Yr4 resistance gene was present in several cultivars in the past (e.g., Maris Beacon, Rapier, Avalon or Brimstone [45-47]). In fact, the Yr4 has also been postulated for certain Danish wheat cultivars [48]. This suggests that the vir4 gene may even have a selective advantage at a larger, European scale and that simple hitch-hiking is not the only explanation for its presence in the French population. It further implies that migration at larger geographical scales, such as that 
(a)

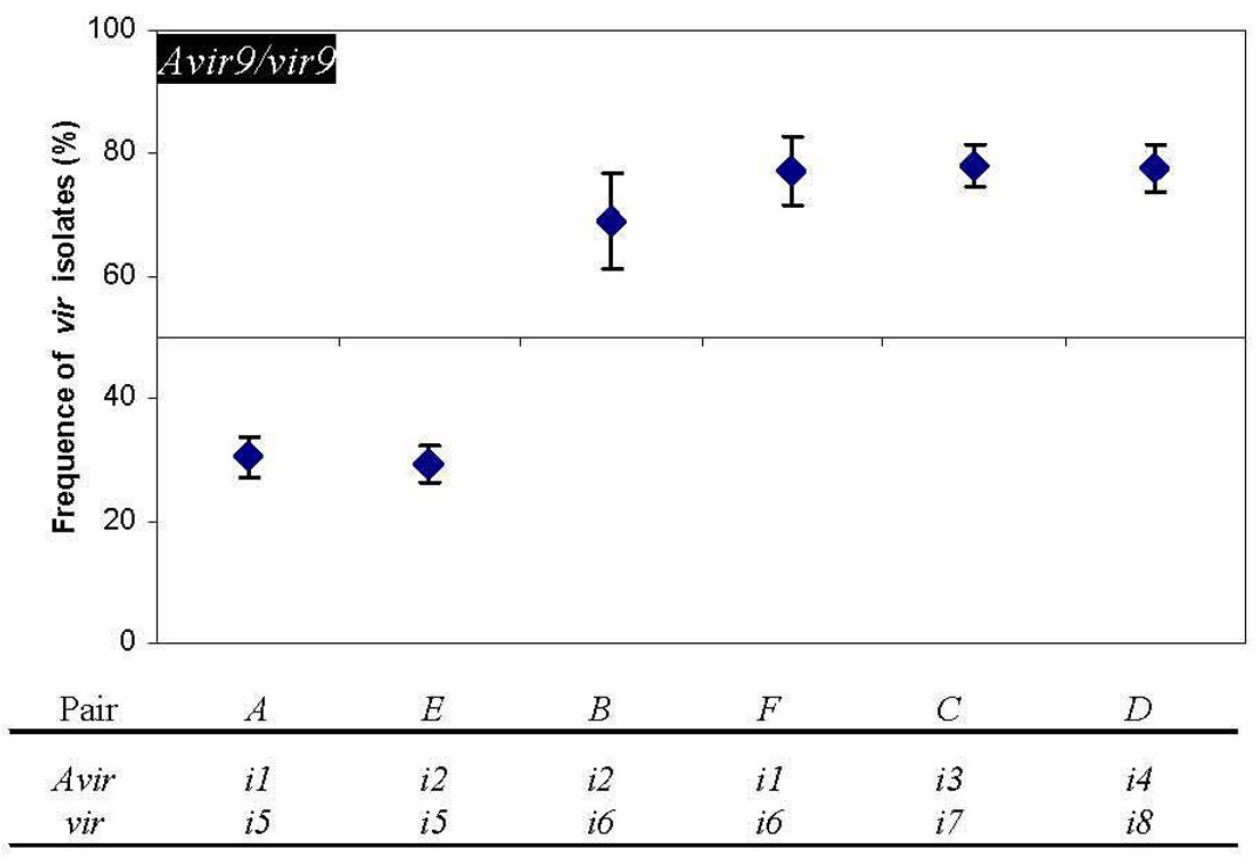

(b)

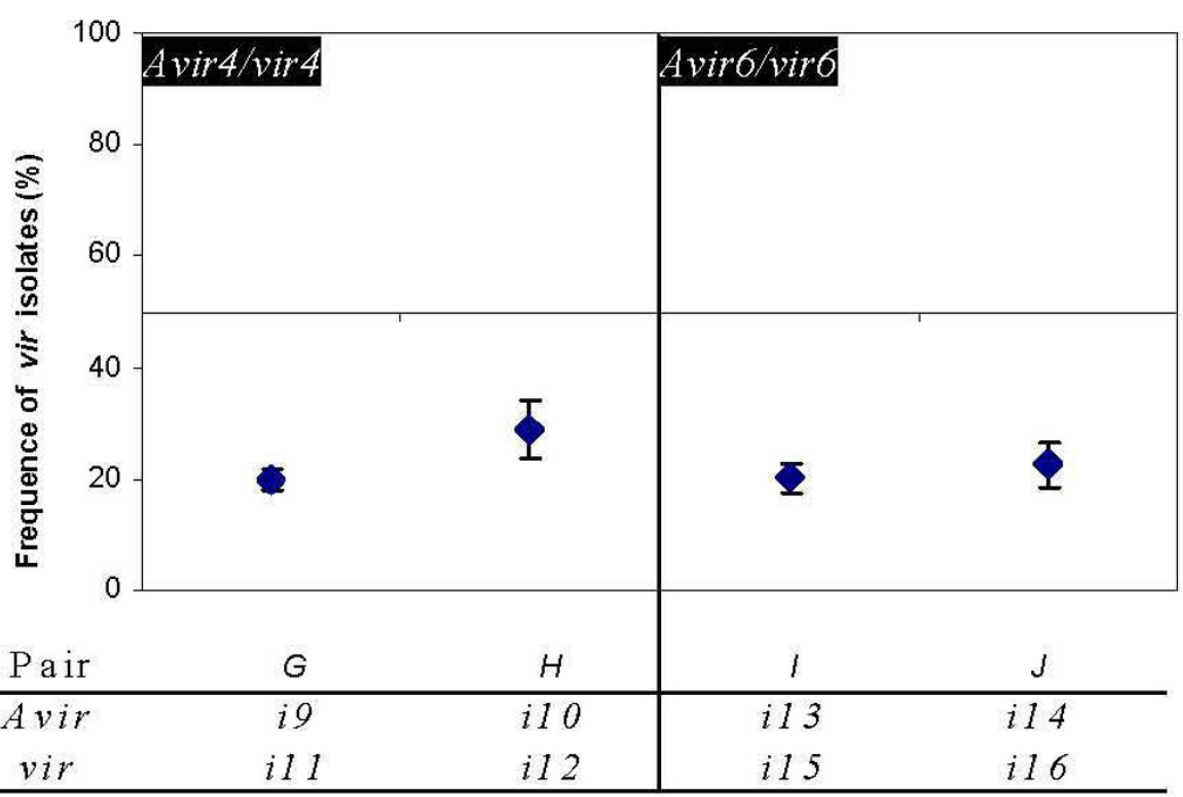

Figure 2

Competitive success of virulent isolates in field experiments. Mean ( \pm S.E.) frequencies of vir9 (a), vir4 and vir6 (b) isolates relative to their corresponding avirulent (Avir) isolates, as determined in pairwise competition experiments. Competing pairs (A-J) of virulent (vir) and avirulent (Avir) isolates ( $I I-i / 6)$ were started at an initial 50:50 ratio and the relative frequency of the vir isolate measured at the end of the growing season. Each point represents the means and S.E. calculated over 2 years and 2 host cultivars. For all 10 pairs, final frequencies were significantly different from the initial 50:50 ratio $\left(t_{7}>3.49 ; p<0.010 I\right)$. 


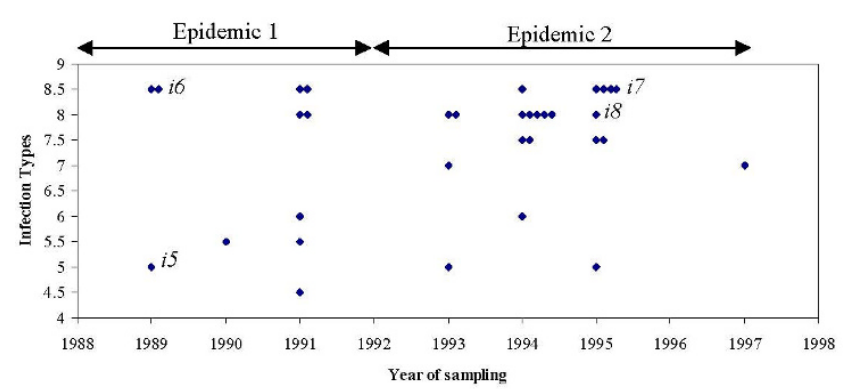

\section{Figure 3}

Time series of aggressiveness of vir9 isolates. Infection types on Clement seedlings of 33 isolates carrying the vir9 gene and collected from French populations during two epidemic periods between 1989 and 1997. Large values of infection type indicate high levels of sporulation and thus high aggressiveness. Each point represents the mean of two independent measurements. Four isolates (i5-i8) were used in the field competition experiments.

between the UK and continental Europe [33,35], can influence local pathogen population structure and evolution.

For the vir9 gene, the story is more complex. After the resistance breakdowns in 1989 and 1994 and subsequent withdrawal of the susceptible cultivars, vir9 did not decrease in frequency, and currently all known PST pathotypes are fixed for this redundant virulence gene [48]. In part, this can be explained by its hitch-hiking with a newly arisen virulence gene (vir17, [34,35]), just like in the case of the vir4 gene. Moreover, we detected a fitness cost only for one virg isolate, while the other three isolates were even more competitive than their avirulent counterparts not carrying the vir9 gene. Our results further indicate that these differences are due to variation in aggressiveness and sporulation rates. The three successful isolates sporulate at high rates, while the less competitive one is among the least aggressive isolates of the vir9 collection.

Why is the vir9 gene costly in some isolates, but not in others? The answer may lie either in the gene itself or in its genetic background. First, in our four virulent isolates, the same vir9 virulence phenotype may represent different mutations, and only one imposes a fitness cost. Typically, virulence genes arise from mutations disrupting some metabolic function that would otherwise elicit a resistance reaction. It is conceivable that different mutations can bring about such modifications, and possibly not all of them come at a fitness cost [43]. Alternatively, costs of virulence may have been balanced by compensatory mutations. Compensation may occur directly in the gene(s) responsable for the loss of function, but also indirectly in genes determining pathogen aggressiveness. Indeed, aggressiveness is known to have a multigenic basis [49], thus offering multiple targets for compensatory mutations. If fitness effects are sufficiently large and selection efficient, this may even bring about a net positive effect and overcompensation of the cost of virulence. The history of the vir9 gene is compatible with such a scenario. Resistance breakdown of the $\mathrm{Yr} 9$ gene in England occurred already two years before highly aggressive vir9 variants appeared in France. Breakdowns are usually accompanied by massive PST epidemics, with exponential population growth and up to 10 infection cycles per growing season. This may have provided sufficient time for compensatory mutations to arise in the vir9 background and to be picked up by natural selection. Indeed, for the period in question, a signature of this process can be seen by the increase of the frequency of highly aggressive isolates in the vir9 spore collection. So far, cost-compensation has been described for resistance to antibiotics[50] or insecticides [51]. If our interpretations are correct, this study is one of the first to suggest the compensation of costs of virulence in natural populations of a pathogen. Similar ideas about the progressive evolution of the fitness of new pathotypes of cereal rusts date back to the 1970s. Based on empirical and experimental data, it was suggested that new phenotypes were unable to spread because of their low aggressiveness $[52,53]$ and that adaptation to quantitative host resistance occurred gradually through polygenic changes [54].

Interestingly, we did not detect variation in neutral genetic markers among the isolates in the collection, despite the large number of primer combinations screened. As these isolates share the same clonal background, variation in both virulence and aggressiveness must have arisen within a relatively short time span. Indeed, Lande and Barrowclough [55] showed that in very large populations, heritable variation in quantitative traits can established by spontaneous mutation without leaving a trace in neutral genetic markers. Clearly, this rapid evolutionary change sets limits to our "all-else-being-equal" approach in the competition experiments, aiming at the comparison of isogenic isolates that differ only in the virulence gene in question.

\section{Conclusion}

First, our study demonstrates substantial fitness costs of single virulence genes on different host varieties under field conditions. In part, these costs explain changes in the genetic composition of natural PST populations, consistent with van der Plank's hypothesis of selection against redundant virulence genes [21]. Second, however, we also found that redundant virulence genes are not automatically selected against, either because they do not have a fitness cost or because costs are compensated. Regardless of the precise mechanism, one of our main conclusions is 
that the fate of a particular virulence mutation may not be independent of its genetic background. This is particularly relevant for clonal pathogens, such as PST, where the whole genome is a single linkage group exposed to natural selection. Selection then perceives the sum of the costs of the different virulence genes carried by a given genotype and that of all other genes determining growth and transmission. Indeed, additional virulences may have more deleterious effects in genetic backgrounds that already carry other virulence genes $[40,42,56]$ as it was the case in our study. The very different outcomes for the three virulence genes studied here indicate strong variation in the evolutionary trajectories of virulence mutations; this also stresses the need for more refined theoretical models to predict these trajectories.

Third, our results have implications for plant breeding strategies. Current large-scale programs employ inter-specific crosses and molecular engineering to develop resistance genes imposing a high cost of virulence for pathogens that overcome this resistance. This handicap may prevent the spread of such pathogen genotypes and thus increase the durability of resistance [57]. Obviously, this approach critically hinges on the consistency and durability of costs of virulence. Our experiments indicate that costs can be quite consistent, at least for certain virulence genes. However, durability of costs of virulence can be expected to be inversely proportional to the strength of selection imposed on the pathogen to compensate these costs. We suspect that that compensation may occur rather rapidly, by hitch-hiking processes or by efficient selection on multigenic traits. Thus, if demonstrating the cost of virulence is already complicated, predicting its durability may be even more difficult.

Finally, it is often argued that agro-patho-systems are too artificial or too simple to be comparable to natural hostparasite systems. Here, we demonstrated that the seemingly straightforward genetic architecture of the cultivated host produces complex patterns of genetic change in its natural opponent. These evolutionary changes can be investigated experimentally in real-time (several pathogen generations) and they remain traceable over larger time scales in the production areas (years or decades). We therefore believe that the study of these systems can provide valuable general insights in the costs and consequences of adaptation in host-parasite systems.

\section{Methods}

\section{Species description}

Puccinia striiformis f.sp. tritici (order Uredinales, class Basidiomycetes) is strongly wheat-specific (Triticum aestivum and T. turgidum). There is no known alternate host on which the sexual cycle could be completed and thus fungal reproduction is essentially asexual. Fungal mycelia systemically grow within leaf nervures (stripes); the asexual part of the life cycle is completed within only 14 days, resulting in repeated bursts of sporulating lesions releasing urediospores that infect neighbouring plants. Typically, these clonal fungal populations experience strong between-season bottlenecks every season, and from low initial genetic diversity, new virulence mutations arise during seasonal epidemics. In Europe, resistance breakdown usually takes only 3-4 years [35]. Even if treated the yield loss can reach $80 \%$ [58]. To date, a complete phylogeny of this species is still lacking, but introductions of new strains occur worldwide and can be attributed to both long distance wind dispersal and accidental human contamination.

\section{Competition experiments}

We used 16 isolates collected as uredospores from infected fields in the North of France, between 1989 and 1997 (Table 1), and stored in liquid nitrogen. Virulence gene profiles were characterised on European and World differential cultivars, using Johnson et al.'s method [59]. We used 39 AFLP primer combinations to characterise phylogenetic relationships among the isolates [see Additional file 1]. Thus, competing pairs of virulent and avirulent isolates of the vir9 and vir6 pathotypes represented indistinguishable AFLP genotypes; for the vir4 pathotype, competing isolates differed by four AFLP bands and may therefore carry other mutations in addition to the virulence for Yr4.

We tested 8 virulent isolates, four carrying the vir9 virulence gene and two with the vir4 and vir6 virulence genes, respectively. Each virulent isolate was paired with an avirulent isolate as a competitor (Pairs A-J, Table 1). Most pairs were competed on two host cultivars and in two growing seasons $(2005,2006)$ under field conditions. Pairs $A$ and $B$ were also tested under climate chamber conditions. We established two independent replicates per pair, year and host cultivar.

\section{Preparation of inocula}

To produce fresh inocula for the experiments, uredospores were taken out of the liquid nitrogen, heat shocked $\left(40^{\circ} \mathrm{C}, 15 \mathrm{~min}\right)$ and used to inoculate 7-day-old seedlings of the susceptible cultivar Victo. Inoculated plants were incubated in a dew chamber at $8^{\circ} \mathrm{C}$ for $16 \mathrm{~h}$ in the dark to facilitate infection ([60] and then transferred to the greenhouse (day: $16 \mathrm{~h}, 350 \mu \mathrm{E} \cdot \mathrm{m}^{-2} \cdot \mathrm{s}^{-1}$, $17^{\circ} \mathrm{C}$; night: $8 \mathrm{~h}, 14^{\circ} \mathrm{C}$ ). Eighteen days after inoculation, spores were collected with a vacuum collector, dried in a desiccator for 3 days at $4{ }^{\circ} \mathrm{C}$ and stored in microtubes at $80^{\circ} \mathrm{C}$ prior to the experiments.

\section{Climate chamber experiment (Pairs A and B, vir9 virulence gene)}

For each replicate, a 50:50 mixture of $20 \mathrm{mg}$ uredospores of the virulent and avirulent isolate was inoculated on 
approx. 400 7-day-old seedlings of a given host cultivar. We used two susceptible wheat varieties, Thésée (carrying the Yr2 resistance gene) and Récital (Yr6) [61]. We chose these cultivars because of their high susceptibility at the time of the appearance of the vir9 virulence in 1989. After incubation in a dew chamber at $8^{\circ} \mathrm{C}$ for $16 \mathrm{~h}$, plants were placed in a climate chamber (day: $16 \mathrm{~h}, 350 \mu \mathrm{E} \cdot \mathrm{m}^{-2} \cdot \mathrm{s}^{-1}$, $17^{\circ} \mathrm{C}$; night: $8 \mathrm{~h}, 14^{\circ} \mathrm{C}$ ). Twenty days after inoculation, spores were collected and used to start a new infection cycle on the same host cultivar, as described above. We ran five cycles of competition and preserved a small sample of spores at each cycle to estimate the relative frequencies of the competing isolates.

\section{Field experiments}

Field experiments were conducted during two wheat seasons in 2005 and 2006, at the Grignon Institute in Northern France $\left(48^{\circ} 50^{\prime} \mathrm{N} 1^{\circ} 55^{\prime} \mathrm{E}\right)$. A replicate consisted of a 10 $\times 1.5 \mathrm{~m}$ plot, (250 plants $/ \mathrm{m}^{2}$ ) of a given host cultivar. Experiments were started in late March, at the end of tillering. In the center of the plot, we planted two sporulating Victo seedlings that had been inoculated with a 50:50 mix of the two competing isolates, as described above. Preliminary tests showed that sporulation on the Victo seedlings did not significantly change the 50:50 ratio (data not shown). At the end of the epidemic (early June), uredospores were harvested and stored at $-80^{\circ} \mathrm{C}$ until further processing. The absence of infection in surrounding plots indicated that natural or cross-contamination did not occur.

\section{Frequency assessment}

Frequency assessments of the competing isolates followed the protocol by Lannou et al. (2005). For a given sample, we used an oil solution of $0.1 \mathrm{mg}$ of the collected uredospores to inoculate five pots, each with 15 seedlings of a discriminating host cultivar. The cultivars Sleipner (Yr9 resistance gene), Heines Kolben (Yr2, Yr6) and Hybrid 46 $(\mathrm{Yr} 4)$ were used for experiments with vir9, vir6 and vir4 virulence genes, respectively. On these discriminant cultivars, the virulent isolate develops sporulating lesions, whereas the avirulent isolate produces non-sporulating chloroses, indicating the failure of infection. Thus, the total number of chloroses was counted 7 days and sporulating lesions 14 days after inoculation. The frequency of the virulent isolate in the sample was taken as the ratio of sporulating chloroses/total chloroses. Each frequency was estimated on 400 chloroses on average. The goodness of the frequency assessment was previously validated for Heines Kolben and Hybrid 46 [62]. For Sleipner, we controlled the reliability of frequency estimates by the inoculation of different ratios of Avirulent/virulent isolates [100/0; 75/25; 50/50; 25/75 and 0/100, see Additional file 2].

\section{Estimation of the cost of virulence}

We calculated the selective value $(s)$ of the avirulent isolate from a model by Leonard [28], with $\operatorname{Ln}\left(\mathrm{q}_{\mathrm{n}} /\left(1-\mathrm{q}_{\mathrm{n}}\right)\right)=$ Ln $\left(\mathrm{q}_{0} /\left(1-\mathrm{q}_{0}\right)\right)-\mathrm{n} \operatorname{Ln}(1-\mathrm{s}) ; \mathrm{q}_{0}$ is the initial frequency of the virulent isolate in the mix and $\mathrm{q}_{\mathrm{n}}$ its final frequency after $n$ generations and (1-s) is the fitness difference between the virulent and the avirulent isolate. Following McGregor and Manners [63], the number of fungal generations $n$ in the field experiments was estimated by fitting the duration of latent period ( $\mathrm{p}$ ) on the mean yearly temperature $(\mathrm{T})$ at the Grignon site as: $\mathrm{p}=28,24 \exp (-0,06 \mathrm{~T})$. From this, we obtained an estimate of five fungal generations in both years.

\section{Analysis of the collection of vir9 isolates}

Of the 33 vir9 isolates analysed here, 11 were collected early after the first appearance of this pathotype in France (1989-1991). In 1992, this first epidemic was ended by a severe drought, and the remaining isolates were collected during the second epidemic period (1992-1997). The isolates all have the same virulence gene profile, as confirmed by previous analysis using the World and European differential cultivars as well as by our own tests using supplementary cultivars [Federationx4Kavkaz (Yr9), Sleipner (Yr9+), Austerlitz (Yr6+), Early Premium, Anza]. Isolates had been stored at $-80^{\circ} \mathrm{C}$ and fresh uredospores were prepared as described above.

We used AFLP markers to investigate the neutral genetic diversity among the isolates. Ten combinations of PstI and MseI primers with two selective nucleotides were used. A subset of eight isolates was screened with 24 additional primer combinations with two selective nucleotides. The four isolates used in the competition experiments were tested with all 39 AFLP combinations. Genomic DNA extraction, DNA quantification on agarose gel and AFLP genotyping are described in detail by Enjalbert et al. [34,64].

Variation in aggressiveness was measured as follows. Seedlings of the Clement cultivar were grown in groups of five plants in $1 \mathrm{dm}^{3}$ pots in the greenhouse $\left(14^{\circ} \mathrm{C}-8 \mathrm{~h}\right.$ dark period and $17^{\circ} \mathrm{C}-16 \mathrm{~h}$ light period). When primary leaves were fully expanded, pots were exposed to a $16 \mathrm{~h}$ light regime and two pots per isolate were inoculated with $0.2 \mathrm{mg}$ of uredospores, suspended in $300 \mu \mathrm{l}$ of Soltrol $[60,65]$. After incubation in a dark dew chamber for $24 \mathrm{~h}$ at $8^{\circ} \mathrm{C}$, seedlings were placed back in the greenhouse. Fifteen days after inoculation, the primary leaf of each seedling was examined visually for the infection type according to a scale from 0 (no symptoms) to 9 (high sporulation) [66]. 
To calibrate the infection type index, we measured the sporulation rate of 11 isolates, including those from the competition experiment $(i 5, i 6, i 7, i 8)$. Groups of $10 \mathrm{Clem}$ ent seedlings were grown in $5 \mathrm{~cm}^{2}$ pots, as described above. At the 2-leaf stage ( 8 days), seedlings were thinned to 6 individuals per pot and exposed to a $16 \mathrm{~h}$ light regime. The second leaf from each seedling was removed and the first leaf attached horizontally, adaxial side up, on a Plexiglas sheet with plasticine (Ulmann, Paris, France) [60]. Seedlings from 10 pots were inoculated together in a settling tower [67], with $5 \mathrm{mg}$ spores of a given isolate $(\approx$ 52 spores deposited per $\mathrm{cm}^{2}$ ). After incubation, seedlings were kept in a climate chamber, as described above. Eight days after their opening, we counted the number of lesions and estimated the inoculated part of the leaf surface estimated (width $\times$ length) on two leaves per pot, from which we calculated the lesion density per $\mathrm{cm}^{2}$. The pots were then placed individually under plastic jars to prevent cross-contamination. Uredospores were collected 17 and 22 days after inoculation, dried for $24 \mathrm{~h}$ at $5^{\circ} \mathrm{C}$ and then weighed. For each pot, we calculated sporulation rate as the ratio of spore production (mg) over lesion density.

\section{Statistical analyses}

Changes in (arcsine-transformed) frequency of virulent isolates in the climate chamber competition experiment were analysed by means of a repeated measure ANOVA, using the MIXED procedure of SAS statistical software [68]. Variation in final frequencies of virulent isolates in the field competition experiments were analysed by means of Analysis of Deviance, based on a logistic regression (GENMOD procedure; SAS). Fully factorial statistical models contained the identity of competing pairs (Pair $A, B$, etc.), host cultivar and year. In all analyses, frequencies for a given replicate represented combined values over all pots and plants of the discriminating cultivar. We further used $t$-tests to test whether the final frequency of virulent isolates was significantly different from 0.5 across all replicates and pairs. Frequencies in the 1:1 mixtures at the beginning of the experiments were not significantly different from 0.5 (not shown). One-way ANOVAs were employed to compare differences in mean and variance of infection type among isolates from the two epidemic periods.

\section{Authors' contributions}

$\mathrm{BB}$ carried out the study in controlled conditions and field experiments. $\mathrm{BB}, \mathrm{OK}$ and JE analyzed the results, performed the statistical analysis and drafted the manuscript. ML participated in the design and coordination of the experiments. JE and CP designed the study and CP helped to draft the manuscript. All authors read and approved the final manuscript.

\section{Additional material}

\section{Additional file 1}

Phylogenetic relationships between PST isolates used in competition. The table (a) shows the list of the 39 primer combinations used for AFLP analysis. The most parsimonious tree (b), built on the basis of AFLP polymorphism, revealed low divergence between two clonal lineages, while within each lineage, no molecular divergence was found between isolates differing by a single virulence. Each race is coded by its combination of virulences against corresponding specific resistance genes ( $\mathrm{Yr} 1, \mathrm{Yr} 2$ and so on).

Click here for file

[http://www.biomedcentral.com/content/supplementary/1471-

2148-9-26-S1.doc]

\section{Additional file 2}

Validation of the use of Sleipner cultivar to assess vir9 proportion in spore mixtures. The figure shows the reliability of frequency estimates on $c v$. Sleipner after inoculation with different ratios of Avir9/vir9 isolates. For two independent pairs of Avir9/vir9 isolates, we prepared spore mixtures containing different proportions of the vir9 isolate: $0 \%, 25 \%, 50 \%$, $75 \%$ and $100 \%$. For each isolate pair and proportion, two independent inoculations were performed over 5 pots, each containing 10 to 15 seedlings. After 10 days, the frequency of the virulent isolate was measured (see Methods, "frequency assessment").

Click here for file

[http://www.biomedcentral.com/content/supplementary/14712148-9-26-S2.doc]

\section{Acknowledgements}

We thank Cécile Hamès, Nathalie Galet and Laurent Gerard for their help during the experimentations, as well as Aurélien Tellier and two anonymous reviewers for their comments on the manuscript. This work was supported by the European Integrated Project Bioexploit, FOOD-CT-2005513959. The first author was supported by a grant from the "Institut Français de Coopération" in Tunisia.

\section{References}

I. Bell G: Selection: the mechanism of evolution. New York: Chapman \& Hall; 1997.

2. Stearns SC: The evolution of life histories. Oxford: Oxford University Press; 1992.

3. Kassen R: The experimental evolution of specialists, generalists and the maintenance of diversity. Journal of Evolutionary Biology 2000, I 5(173-190):

4. Brown JKM: Little else but parasites. Science 2003, 299(56I3): 1680-I68I.

5. Frank SA: Coevolutionary genetics of plants and pathogens. Evolutionary Ecology 1993:45-75.

6. Sasaki A: Host-parasite coevolution in a multilocus gene-forgene system. Proceedings of the Royal Society of London Series B-Biological Sciences 2000, 267(1458):2।83-2।88.

7. Bergelson J, Dwyer G, Emerson JJ: Models and data on plantenemy coevolution. Annu Rev Genet 200I, 35:469-499.

8. Segarra A: Stable polymorphisms in a two-locus gene-for-gene system. Phytopathology 2005, 95:728-736.

9. Orgil U, Arakit H, Tangchaiburana S, Berkey R, Xiao S: Intraspecific genetic variations, fitness cost and benefit of RPW8, a disease resistance locus in Arabidopsis thaliana. Genetics 2007, 176:2317-2333.

10. Burdon JJ, Thrall PH: The fitness costs to plants of resistance to pathogens. Genome Biology 2003, 4(9):. 
II. Chao L, Levin B, Stewart F: A complex community in a simple habitat: an experimental study with bacteria and phage. Ecology 1977, 58:369-378.

12. Lennon JT, Khatana SAM, Marston MF, Martiny JBH: Is there a cost of virus resistance in marine cyanobacteria? The ISME journal 2007, I:300-312.

13. Lohse K, Gutierrez A, Kaltz O: Experimental evolution of resistance in Paramecium caudatum against the bacterial parasite Holospora undulata. Evolution 2006, 60(6): I I77-I I86.

14. Kraaijeveld AR, Godfray HC): Trade-off between parasitoid resistance and larval competitive ability in Drosophila melanogaster. Nature 1997, 389:278-280.

I5. Leonard KJ: Genetic equilibria in host-pathogen systems. Phytopathology 1969, 59( (12): I858.

16. Person C, Groth JV, Mylyk OM: Genetic change in host-parasite populations. Annual Review of Phytopathology 1976, I4: I77-188.

17. Abramovitch RB, Anderson JC, Martin GB: Bacterial elicitation and evasion of plant innate immunity. Nature Reviews, Molecular Cell Biology 2006, 7:601-6II.

18. Cruz CMV, Bai JF, Ona I, Leung H, Nelson RJ, Mew TW, Leach JE: Predicting durability of a disease resistance gene based on an assessment of the fitness loss and epidemiological consequences of avirulence gene mutation. Proceedings of the Nationa Academy of Sciences of the United States of America 2000, 97(25): I 3500-I3505.

19. Jenner CE, Wang XW, Ponz F, Walsh JA: A fitness cost for Turnip mosaic virus to overcome host resistance. Virus Research 2002, 86(I-2): I-6

20. Huang YJ, Li ZQ, Evans N, Rouxel T, Fitt BDL, Balesdent MH: Fitness cost associated with loss of the AvrLm4 avirulence function in Leptosphaeria maculans (Phoma stem canker of oilseed rape). European Journal of Plant Pathology 2006, I I 4( I):77-89.

21. Van der Plank JE: Disease resistance in plants. Academic Press, New York and London; 1968:206.

22. Gandon S: Local adaptation and the geometry of host-parasite coevolution. Ecology Letters 2002, 5(2):246-256.

23. Tellier A, Brown JKM: Stability of genetic polymorphism in host-parasite interactions. Proc $R$ Soc Lond Ser B Biol Sci 2007, 274:809-8I7.

24. Flor $\mathrm{HH}$ : The current status of the gene-for-gene concept. Annual Review of Phytopathology 1971, 9:275-296.

25. Grant MW, Archer SA: Calculation of selection coefficients against unnecessary genes for virulence from field data. Academic press, New York 1983, 73(4):547-55I

26. Tiffin P, Hacker R, Brandon SG: Population genetic evidence for rapid changes in intraspecific diversity and allelic cycling of a specialist defense gene in Zea. Genetics 2004, I 68:425-434.

27. Thrall PH, Burdon J): Evolution of virulence in a plant host-pathogen metapopulation. Science 2003, 299(56 I3): I735-I737.

28. Leonard KJ: Selection in heterogeneous populations of Puccunia graminis f.sp. avenae. Phytopathology |969:|85|-|857.

29. Kolmer JA: Selection in a heterogeneous population of Puccinia recondita f.sp. tritici. Phytopathology 1993, 83(9):909-9|4.

30. Bronson $\mathrm{CR}$, Ellingboe $\mathrm{AH}$ : The influence of 4 unnecessary genes for virulence on the fitness of Erysiphe graminis f.sp. tritici. Phytopathology 1986, 76(2): I54-158.

31. Singh DV, Huerta-Espino J: Global Monitoring of wheat rusts, and assessment of genetic diversity and vulnerability of popular cultivars. CYMMIT program 1999-2000 2000 [http://www.cim myt.org/Research/Wheat/map/research results/ResHighlights/ pdfresHigh GlobMonit.pdf].

32. Wellings CR, Mclntosh RA: Puccinia striiformis f.sp. tritici in Australia: pathogenic changes during the first 10 years. Plant Pathology 1990, 39:316-325

33. Hovmøller MS, Justesen AF, Brown JKM: Clonality and long-distance migration of Puccinia striiformis f.sp. tritici in northwest Europe. Plant Pathology 2002, 5 I (I):24-32.

34. Enjalbert J, Duan X, Leconte M, Hovmøller MS, de Vallavieille-Pope C: Genetic evidence of local adaptation of wheat yellow rust (Puccinia striiformis f.sp.tritici) within France. Molecular Ecology 2005, I 4(7):2065-2073.

35. Bayles RA, Flath K, Hovmøller MS, de Vallavieille-Pope C: Breakdown of the $\mathrm{Yr} I 7$ resistance to yellow rust of wheat in northern Europe. Agronomie 2000, 20(7):805-8II.
36. Poulin R, Combes C: The concept of virulence: Interpretations and implications - Comment. Parasitology Today 1999 , I 5( 1 2):474-475.

37. Bubliy OA, Loeschcke V: Effect of low stressful temperature on genetic variation of five quantitative traits in Drosophila melanogaster. Heredity 2002, 89:70-75.

38. Lynch $M$, Walsh $B$ : Genetics and analysis of quantitative traits. Sunderland Massachusetts: Sinauer Associates Incorporated. Molecular Plant-Microbe Interactions 1998, I3(I 2): I322-I329.

39. Bai JF, Choi SH, Ponciano G, Leung H, Leach JE: Xanthomonas oryzae pv. oryzae avirulence genes contribute differently and specifically to pathogen aggressiveness. Molecular Plant-Microbe Interactions 2000, I 3( I 2): I 322-I 329.

40. Lin NC, Martin GB: An avrPtolavrPtoB mutant of Pseudomonas syringae pv. tomato DC3000 does not elicit Pto-mediated resistance and is less virulent on tomato. Molecular Plant Microbe Interaction 2005:43-5I.

4I. Wichmann G, Bergelson J: Effector genes of Xanthamonas axonopodis pv. vesicatoria promote transmission and enhance other fitness traits in the field. Genetics 2004, I 66(2):693-706.

42. Yang YN, Yuan QP, Gabriel DW: Watersoaking function(s) of $\mathrm{Xcm} H \mathrm{I} 005$ are redundantly encoded by members of the Xanthomonas avr/pth gene family. Molecular Plant-Microbe Interactions 1996, 9(2): I05-II3.

43. Shan LB, He P, Zhou JM, Tang XY: A cluster of mutations disrupt the avirulence but not the virulence function of AvrPto. Molecular Plant-Microbe Interactions 2000, I3(6):592-598.

44. Hovmøller MS, Justesen AM: Rates of evolution of avirulence phenotypes and DNA markers in a northwest European population of Puccinia striiformis f.sp. tritici. Molecular Ecology 2007, 1 6:4637-4647.

45. Bayles RA, Stigwood PL: Yellow rust of wheat. UK cereal pathogen virulence survey 1991:13-18.

46. Bayles RA, Stigwood PL: Yellow rust of wheat. UK cereal pathogen virulence survey 1990: I5-20.

47. Bayles RA, Channell MH, Stigwood PL: Yellow rust of wheat. UK cereal pathogen virulence survey 1989:II-17.

48. Hovmøller MS: Sources of seedling and adult plant resistance to Puccinia striiformis f.sp. tritici in European wheats. Plant Breeding 2007, I 26:225-233.

49. Duarte E, Clarke D, Mova A, Domingo E, Holland J: Rapid fitness losses in mammalian RNA virus clones due to Muller's ratchet. Proceedings of the National Academy of Science of the United States of Americia 1992, 89:6015-6019.

50. Andersson $\mathrm{DI}$, Levin BR: The biological cost of antibiotic resistance. Current Opinion in Microbiology 1999, 2(5):489-493.

51. Raymond M, Berticat C, Weill M, Pasteur N, Chevillon C: Insecticide resistance in the mosquito Culex pipiens: what have we learned about adaptation? Genetica 200 I, I I 2:287-296.

52. Roelfs AP, Rothman PG: Races of Puccinia graminis f.sp. avenae in the U.S.A during 1975. Plant Disease Reporter 1976 60(8):703-706

53. Roane CW, Stakman EC, Loegering WQ, Stewart DM, Watson WM: Survival of physiologic races of Puccinia graminis var. tritici on wheat near barberry bushes. Phytopathology 1960, 50:40-44.

54. Clifford BC, Clothier RB: Physiologic specialization of Puccinia hordei on barley hosts with non-hypersensitive resistance. Transactions of the British Mycological Society 1974, 63:42 I-430.

55. Lande R, Barrowclough GF: Effective population size, genetic variation, and their use in population management. In Viable Populations for Conservation Edited by: Soulé ME. Cambridge Cambridge University Press; 1987:87-123.

56. Tellier A, Brown JKM: Polymorphism in multilocus host-parasite coevolutionary interactions. Genetics 2007, 177:1777-1790.

57. Leach JE, Cruz CMV, Bai JF, Leung H: Pathogen fitness penalty as a predictor of durability of disease resistance genes. Annual Review of Phytopathology 200 I, 39:187-224.

58. Murray GM, Ellison PJ, Watson A, Cullis BR: The relationship between wheat yield and stripe rust as affected by lengh of epidemic and temperature at the grain development stage of crop growth. Plant Pathology 1994, 43:397-405.

59. Johnson R, Stubbs RW, Fuchs E, Chamberlain NH: Nomenclature for physiologic races of Puccinia striiformis infecting wheat. Transactions of the British Mycological Society 1972, 58:475-480.

60. de Vallavieille-Pope C, Huber L, Leconte M, Goyeau H: Comparative effects of temperature and interrupted wet periods on 
germination, penetration, and infection of Puccinia recondita f.sp. tritici and $P$. striiformis on wheat seedlings. Phytopathology 1995, 85:409-4I5.

61. de Vallavieille-Pope C, Picard-Formery H, Radulovic S, Johnson R: Specific resistance factors to yellow rust in seedlings of some French wheat varieties and races of Puccinia striiformis Westend. in France. Agronomie 1990, 10:103-1 I3.

62. Lannou C, Hubert P, Gimeno C: Competition and interactions among stripe rust pathotypes in wheat-cultivar mixtures. Plant Pathology 2005, 54(5):699-7I 2.

63. McGregor AJ, Manners JG: The effect of temperature and light intensity on growth and sporulation of Puccinia striiformis on wheat. Plant Pathology 1985, 34(2):263-27I.

64. Enjalbert J, Duan X, Giraud T, Vautrin C, de Vallavieille-Pope C, Solignac M: Isolation of twelve microsatellite loci, using an enrichment protocol, in the phytopathogenic fungus Puccinia striiformis f.sp.tritici. Molecular Ecology Notes 2002, 2:563-565.

65. de Vallavieille-Pope C, Huber L, Leconte M, Bethenod O: Preinoculation effect of light quantity on infection efficiency of Puccinia striiformis and $P$. triticina on wheat seedlings. Phytopathology 2002, 92: |308-|3|4.

66. McNeal FH, Konzak CF, Smith EP, Tate WS, Russel TS: A uniform system for recording and processing cereal research data. US Agricultural Research Service 197I, 42:31-I2I.

67. Eyal Z, Clifford BC, Caldwell RM: A settling tower for quantitative inoculation of leaf blades of mature small grain plants with urediospores. Phytopathology 1968, 58:530-531.

68. SAS: SAS Institute, Inc, Cary, NC., SAS/STAT Software, Version 9.I, see. 2003 [http://www.sas.com/technologies/analytics/sta tistics/stat/].

69. Snedecor GW, Cochran WG: Statistical Methods: Ames. lowa: lowa State University Press; 1980.

Publish with Bio Med Central and every scientist can read your work free of charge

"BioMed Central will be the most significant development for disseminating the results of biomedical research in our lifetime. "

Sir Paul Nurse, Cancer Research UK

Your research papers will be:

- available free of charge to the entire biomedical community

- peer reviewed and published immediately upon acceptance

- cited in PubMed and archived on PubMed Central

- yours - you keep the copyright
BioMedcentral 